\title{
MEASURING PERFORMANCE OF INTERNATIONAL JOINT VENTURES
}

\author{
J. Michael Geringer* and Louis Hebert** \\ University of Western Ontario
}

\begin{abstract}
International joint ventures (IJVs) are increasing in frequency and strategic importance. However, efforts to identify variables associated with IJV performance have been constrained by disagreements regarding the comparability and reliability of alternative performance measures and methods. This study tests several hypotheses regarding the reliability and comparability of a range of objective and subjective measures of IJV performance, as well as evaluating the relative utility of different data collection approaches.
\end{abstract}

Joint ventures (JVs) involve two or more legally distinct organizations (the parents), each of which shares in the decisionmaking activities of the jointly owned entity [Geringer 1988]. It is considered to be an international joint venture (IJV) when at least one parent is headquartered outside the venture's country of operation, or if the JV has a significant level of operations in more than one country [Geringer and Hebert 1989].

The use of JVs, in both international and domestic contexts, has been increasing dramatically in recent years [Geringer and Woodcock 1989; Harrigan 1988; Hergert and Morris 1988]. According to Anderson [1990], there have been more JVs and other collaborative ventures announced since 1981 than in all prior years combined. In addition to their frequency, JVs have become a critical concern for international business because of their increased strategic importance. In the past, JVs had often been used to

*J. Michael Geringer (Ph.D., University of Washington) is Assistant Professor of Policy at the University of Western Ontario. Besides the Journal of International Business Studies, his publications have appeared in journals such as the Columbia Journal of World Business, Management International Review, Business Quarterly, JAI Press' International Human Resource Management annual, and the Strategic Management Journal. His research interests include formation and management of international alliances, MNE diversification strategies, technology management, and strategic uses of human resources.

**Louis Hebert (M.Sc., University of Quebec at Trois Rivieres) is a Ph.D. candidate in business policy at the University of Western Ontario. His current research interests center on the strategic management and control of technology, particularly within international joint ventures.

We would like to thank Colette Frayne and three anonymous reviewers for their comments on an earlier draft of this paper.

Received: February 1990; Revised: May \& August 1990; Accepted: September 1990. 
exploit peripheral markets or technologies, and their activities were typically of marginal importance to the maintenance of a parent firm's competitive advantage. However, JVs are increasingly being perceived as critical elements of an organization's business units network, as strategic weapons for competing within a firm's core markets and technologies [Harrigan 1987]. Furthermore, several studies have suggested that these trends toward the increasing frequency and strategic importance of joint ventures, particularly IJVs, are likely to continue during the 1990s [Deloitte, Haskins and Sells International 1989; Anderson 1990].

Despite their increasing importance, IJVs have often encountered performance problems. Indeed, estimates of unsatisfactory IJV performance, defined in a variety of ways as discussed below, have ranged from $37 \%$ to over 70\% [Janger 1980; Killing 1983; Stuckey 1983; Reynolds 1984; Beamish 1985; Coopers \& Lybrand/Yankelovich, Skelly \& White 1986; Kogut 1986; Harrigan 1986; Deloitte, Haskins \& Sells International 1989]. Efforts to identify variables associated with IJV performance, and that might thus be managed in order to influence venture outcomes, have been constrained by continued disagreements regarding the comparability and reliability of alternative performance measures, and the methodology for collecting such data. The objective of this study was thus to develop and test several hypotheses regarding the reliability and comparability of a range of objective and subjective measures of JV performance, as well as evaluating the relative utility of different approaches to data collection.

\section{PRIOR RESEARCH AND HYPOTHESES REGARDING IJV PERFORMANCE}

\section{Objective versus Subjective Performance Measures}

Prior research evidences significant differences in the operationalization of IJV performance. No consensus on the appropriate definition and measure of this concept has yet emerged. Early studies used a variety of financial indicators typically employed in business research, such as profitability, growth and cost position [Tomlinson 1970; Good 1972; Renforth 1974; Dang 1977; Lecraw 1983]. Others have used objective measures of performance such as the survival of the IJV [Franko 1971; Stopford and Wells 1972; Raveed 1976; Killing 1983; Geringer 1990], its duration [Harrigan 1986; Kogut 1988], instability of (significant changes in) its ownership [Franko 1971; Gomes-Casseres 1987], and renegotiation of the JV contract [Blodgett 1987]. Yet, these financial and objective measures embody potential limitations that are critical to evaluation of IJV performance. Indeed, as is the case for private firms and for conglomerates [Dess and Robinson 1984], these data often are not reported, are unavailable, or are only included in consolidated corporate data. In addition, IJV parents commonly generate financial returns through mechanisms other than dividends, including supply contracts, management fees, technology licensing fees, 
royalties and transfer pricing. If available, these figures are seldom incorporated into calculations of IJV financial performance.

Financial and objective measures also may fail to adequately reflect the extent an IJV has achieved its short- and long-term objectives [Killing 1983; Artisien and Buckley 1984; Blodgett 1987]. IJVs may be formed for pursuing a variety of objectives, from technology transfer and joint research to access to materials, new markets or scale economies [Porter and Fuller 1986; Contractor and Lorange 1988]. Many IJVs also operate in contexts where measures of short-term financial performance might suggest that the venture is performing poorly. For example, IJVs formed to develop radical new technologies (e.g., superconductors or bioengineered pharmaceuticals) or new markets (e.g., the Peoples Republic of China or the U.S.S.R.) are often not likely to generate a financial profit for many years, if at all. In such situations, a financial or objective measure is unlikely to accurately capture an IJV's relative performance versus objectives. Chakravarthy [1989] showed that traditional accounting measures, including profitability figures, are unable to statistically discern excellent from ordinary firms. As Anderson [1990] noted, financial measures evaluate only one dimension of performance. Other factors, including qualitative ones, must also be examined in order to adequately evaluate IJV performance. Thus, despite poor financial results, liquidation or instability, an IJV may have been meeting or exceeding its parents' objectives and thus be considered successful by one or all of the parents. Conversely, an IJV may be viewed as unsuccessful despite good financial results or continued stability.

Because of these concerns, Killing [1983], Schaan [1983] and Beamish [1984] used a single-item perceptual measure of a parent's satisfaction with an IJV's performance (e.g., "To what extent has the IJV met the expectations of your firm?'”). The main advantage of this type of measure is its ability to provide information regarding the extent to which the IJV has achieved its overall objectives. In addition, these three authors, as well as Janger [1980], utilized subjective performance measures for each of a limited number of individual dimensions of the IJV. Nevertheless, these types of measures remain subjective and are thus exposed to serious limitations and biases. Many research methods, such as those based on archival or other secondary data sources, do not generally permit collection of these types of data, instead requiring the use of objective performance measures. Furthermore, the consistency between subjective and objective measures of IJV performance is unknown and, while often assumed, has not been formally tested. However, Dess and Robinson's [1984] finding that subjective and objective measures were correlated for traditional organizational forms suggests that this relationship may be found for IJVs as well. This study's first hypothesis can thus be stated as follows:

H1: There will be a significant positive correlation between objective and subjective measures of IJV performance. 


\section{Use of Single versus Multiple Respondents}

To overcome methodological limitations associated with a subjective or perceptual measure of IJV performance, Schaan [1983] and Beamish [1984] proposed collection of data from each parent regarding its level of satisfaction with the IJV. Data collection from more than one respondent may enhance a measure's reliability, but may also confront a myriad of logistical and cost barriers. Researchers may have access to data from one of the parents, or even from the IJV general manager (IJVGM), but seldom and often only with great difficulty from each of the IJV's parents. The key research issue is thus whether data collected from one parent and/or the IJVGM represents a reliable measure of IJV performance and even a reliable estimate of the other partner's perception of this performance.

On this issue, Dess and Robinson [1984] found that multiple respondents evidenced a high degree of agreement in their assessments of their organization's performance. Similarly for IJVs, it may be expected that evaluations of the venture's performance by the organization's members, i.e., the parent firms or the IJVGM, will be consistent. Furthermore, since IJVs are organizations in which ownership and decisionmaking are shared, we can suppose that one element (a parent firm or the IJVGM) of the cooperative venture will evidence some degree of awareness or information regarding the other elements' (parents or IJVGM) satisfaction and assessment of IJV performance. Therefore, one participant's evaluation of the other partner's satisfaction regarding the IJV's performance is expected to be correlated with the partner's actual reported satisfaction. Two hypotheses in this regard can be stated as follows:

$\mathrm{H} 2$ : There will be a significant positive correlation among the parents' and the IJVGM's assessments of IJV performance.

H3: There will be a significant positive correlation between a parent's satisfaction with IJV performance and perceptions by the other partner and the IJVGM of this parent's satisfaction.

\section{Influence of National Culture on Performance Evaluations}

Although positive correlations among parents' assessments of IJV performance are hypothesized, it is also possible that agreement on IJV performance among a venture's participants may be influenced by cultural similarity among them. In fact, several authors have shown or hypothesized that different national cultures embody different attitudes, values and beliefs that find their materialization in distinct business cultures, styles and practices [England 1975; Hofstede 1980; Davidson 1982; Deal and Kennedy 1982; Schein 1985; Schneider 1988]. For example, Ouchi [1981] examined the U.S. and Japanese business cultures and described them as mostly incompatible. The presence of dissimilarities between parent firms' national cultures may be more likely to lead to differences in parent firms' objectives for an IJV, as well as in their approaches to coordination, operating methods and strategy implementation [Root 1982; Sullivan and 
Peterson 1982; Geringer 1988; Brown, Rugman and Verbeke 1989]. These dissimilarities may also lead to differences in the partners' perceptions of each other and the IJV and result in a lower degree of agreement regarding IJV performance.

In contrast, in IJVs where parents are from the same national culture or nation, a tendency toward greater agreement among the parents and the IJVGM regarding the venture's performance is expected. As shown by Anderson and Weitz [1989], cultural similarity promotes communication between business partners. Improved communication should result in greater correlation between their respective assessments of an IJV's performance. It should also lead to stronger correlation between one parent's satisfaction with IJV performance and the assessment by the other partner and the IJVGM of this parent's satisfaction. The study's final two hypotheses can therefore be stated as follows:

H4: Correlation between partners' assessments of IJV performance will be stronger in IJVs involving parents with similar national cultures.

H5: Correlation between a parent's satisfaction with IJV performance and the perception by its partner and the IJVGM of this parent's satisfaction will be stronger in IJVs involving parents with similar national cultures.

\section{METHOD}

The five research hypotheses developed in the preceding section were tested using data collected in two distinct but related studies on IJVs in the United States and Canada, respectively. These two studies were undertaken by the same researchers in consecutive years $[1988 ; 1989]$ and both studied the same dimensions of the management of IJVs in the U.S. and Canada, respectively. In addition to the data collection approach, the two questionnaires were similar and most questions used were identical. However, the sampling frame used for the U.S. study included IJVs which had ceased their operations as well as ventures which were still in existence, while only IJVs still in existence in 1988 could be identified for the Canadian study. This explains why objective performance measures could not be obtained for the Canadian sample. Furthermore, only one parent per IJV was contacted in the U.S. study, while all parents and the IJVGMs were contacted in the Canadian study. As a result, correlations among multiple respondents could not be computed for the U.S. sample.

Sample selection. The study on IJVs in the U.S. focused on two-parent IJVs in manufacturing industries (SIC 20-39) and involving one or more U.S. parent. The focus was further restricted to IJVs with target markets of one or more developed (OECD) country, and which were formed between 1979 and 1985. A listing of such IJVs was obtained from secondary sources (Mergers and Acquisitions; the Wall Street Journal Index; Yearbook on Corporate Mergers, Joint Ventures and Corporate Policy; Predicasts' Funk $\&$ Scott Index of Corporate Change; U.S. Commerce Department's Foreign 
Direct Investment in the United States). It was expected that the resulting sampling frame represented a reasonable approximation of the overall population of these IJVs, and that any selection bias would be minimal.

Due to dispersion of the 1018 qualifying parent firms, the sample was selected from five geographic clusters which contained 547 firms: the San Francisco Bay Area, the Los Angeles-San Diego metroplex, Texas, the Milwaukee-Chicago-Indianapolis metroplexes, and the mid-Atlantic coast region (Virginia to New York). A sample of 109 firms was randomly selected from these clusters. Data were collected in 1988 for 69 ventures $(63 \%)$, including 31 which still existed as IJVs. Forty-five IJVs included a non-U.S. parent firm, including 17 from Japan, 27 from Western Europe and 1 from Canada. Data were only collected from one U.S.-based parent per IJV.

The study on IJVs in Canada examined two- and three-parent IJVs in manufacturing industries. All IJVs were based in Canada, had been formed since 1981, and still existed as IJVs at the end of 1988. The population of JVs was obtained from Statistics Canada data. A sample of $100 \mathrm{JVs}$ was randomly selected from this population listing. The Canadian headquarters of domestic, U.S. and non-North American parent firms, as well as the JVGMs, were contacted in 1989 to assess whether the venture qualified as an IJV (i.e., whether at least one of the parent firms was not Canadian, or if at least $15 \%$ of the JV's sales were to non-Canadian markets). Of 48 qualifying IJVs, data were obtained from multiple respondents (i.e., from the IJVGM and at least one parent or from executives of two parent firms) for 32 IJVs $(67 \%)$. There was a total of 82 useable responses, including 32 IJVGMs and 50 parent company executives.

Data collection method. In both studies, data were collected with similar pre-tested questionnaires, followed by semi-structured interviews to confirm responses. One senior executive from each sample parent firm was contacted. Each parent company respondent had direct responsibility for the IJV's operations and virtually all had been intimately involved with the IJV since its formation. Only for the Canadian study were questionnaires and follow-up interviews conducted with the IJVGMs.

Subjective performance measures. Each parent's satisfaction with the IJV's overall performance was assessed using 5-point Likert-type scales (e.g., "In general, how satisfied has your firm been with the joint venture's overall performance?'). In addition, a 15 -item scale was developed to assess IJV performance versus initial projections along individual venture dimensions (e.g., "For each of the following, rate the joint venture's actual performance versus initial projections at the time the venture was formed"). Performance on each dimension was assessed using 5-point Likert-type scales.

Objective performance measures. Objective IJV performance was measured in three ways: survival, stability and duration. IJV survival was measured using a dichotomous variable based on the survival or nonsurvival of the IJV from the time of its formation until 1988. IJV stability was also 
measured with a dichotomous variable based on whether changes in the division of IJV equity (excluding termination as an IJV) had occurred since the venture's formation. IJV duration was measured based on the number of years between the IJV's formation and either its termination or the collection of performance data, whichever came first. These three variables are the objective measures of performance most frequently used in the joint venture literature. Other objective measures and financial indicators (e.g., profitability, growth and cost position) were not used. In addition to being unavailable, the appropriateness of their use might have been questionable, particularly given the multi-industry nature of the two samples.

For the U.S. sample, thirty-one of the sixty-nine ventures still existed as IJVs in 1988, and seventeen IJVs had been subject to instability in their ownership structure. The average duration of an IJV in the U.S. sample was 4.3 years, including 3.4 years for the terminated ventures and 6.0 years for the surviving IJVs.

Objective measures of IJV performance were not obtained for the Canadian sample, due to the fact that the sampling frame only included IJVs formed since 1981 but still existing in 1988. As a result of this bias toward surviving IJVs, which was necessary in order to obtain adequate response rates from parent firms and especially IJVGMs, only two IJVs had been terminated by the time performance data were collected in 1989 . Thus, relevant and meaningful objective performance measures comparable to those collected for the U.S. sample could not be obtained for the Canadian IJVs. The average age for the Canadian IJVs was 4.7 years.

Cultural similarity. This variable was measured dichotomously, with cultural similarity considered to exist only if all of the IJV's parent firms were headquartered in either Canada or the United States. According to this definition, an IJV involving Canadian and U.S. parents would exhibit cultural similarity. This was the case for seven of the Canadian sample's thirty-two IJVs, while for ten additional IJVs all parents were Canadian companies. There were fifteen IJVs involving at least one parent located outside North America, and thus classified as not exhibiting cultural similarity. This cultural similarity construct is consistent with the one used in Anderson and Weitz [1989].

Data analysis. Spearman rank-order correlation coefficients were computed using SPSS-X in order to test the five research hypotheses. This nonparametric statistic appeared to be the most appropriate alternative considering the nature of the measures used and the samples' and subsamples' sizes. It also permitted testing of the different elements of each hypothesis with a single statistic, rather than having to rely on different statistics whose results would not be directly comparable. Furthermore, to assess reliability of results, Kendall tau-B and Pearson correlation coefficients were computed, and results consistent with the Spearman-based analyses were obtained on each test. Finally, in all analyses, missing values were excluded on an analysis-by-analysis basis. 


\section{RESULTS}

Results for all hypotheses are reported in Tables 1, 2, 3 and 4. Hypothesis 1 was tested on the U.S. sample. Correlations were generally positive and significant between subjective and objective measures of IJV performance (Table 1). IJV survival was the objective measure which evidenced the strongest and most significant correlations with subjective performance measures (both satisfaction-based measures as well as ten of fifteen individual dimensions of performance were significant at 0.05 or less), followed by IJV duration (both satisfaction-based measures and eight of fifteen individual dimensions of performance were significant at 0.05 or less). There were generally stronger correlations between the three objective performance measures and the subjective assessments of overall satisfaction with the IJV's performance and the individual dimensions evaluating overall IJV performance (e.g., sales level, market share, profitability, overall IJV performance). In turn, results for correlations between more specific individual dimensions of IJV performance (e.g., quality control, cost control, labor productivity, customer service) and objective measures were less strong. Indeed, some coefficients for individual dimensions of IJV performance did not evidence significance at the 0.05 level and, for the IJV stability measure, two dimensions evidenced small, nonsignificant relationships in a direction contrary to what had been hypothesized.

Hypotheses 2 and 3 were tested on the Canadian sample and both received support. For nine of fifteen items measuring different aspects of IJV performance, there were significant positive correlations $(p \leq 0.05)$ between the two parent firms' assessments of IJV performance (Table 2). Analysis of the IJVGM's assessments of IJV performance versus similar assessments by Parent 1 and Parent 2, respectively, yielded even stronger results. Significantly positive correlations ( $p \leq 0.05$ ) were obtained for thirteen and twelve of the fifteen items, respectively (Table 3 ). The analyses revealed that correlations tended to be higher between evaluations by the IJVGM and the individual parents than among the parents themselves. Consistent with results for Hypothesis 1, correlations in each of the above analyses were stronger for items measuring general or overall dimensions of IJV performance than for items measuring more specific dimensions of IJV performance. Similarly, a parent's actual reported satisfaction with IJV performance and the perceptions by its partner and the IJVGM of this parent's satisfaction were significantly positively correlated in all cases (Table 4). It was also apparent that the IJVGM's perceptions of one parent's satisfaction were closely correlated with the other partner's perception of this parent's satisfaction.

Furthermore, the anticipated relationships between cultural similarity and IJV performance (Hypotheses 4 and 5) were supported by the results for the Canadian sample. For nine of the fifteen dimensions examined, correlations between partners' assessments of specific aspects of IJV performance were significantly positive as well as being stronger for partners 


\section{TABLE 1}

\section{Spearman Rank Order Correlations Between Objective and Subjective Measures of IJV Performance}

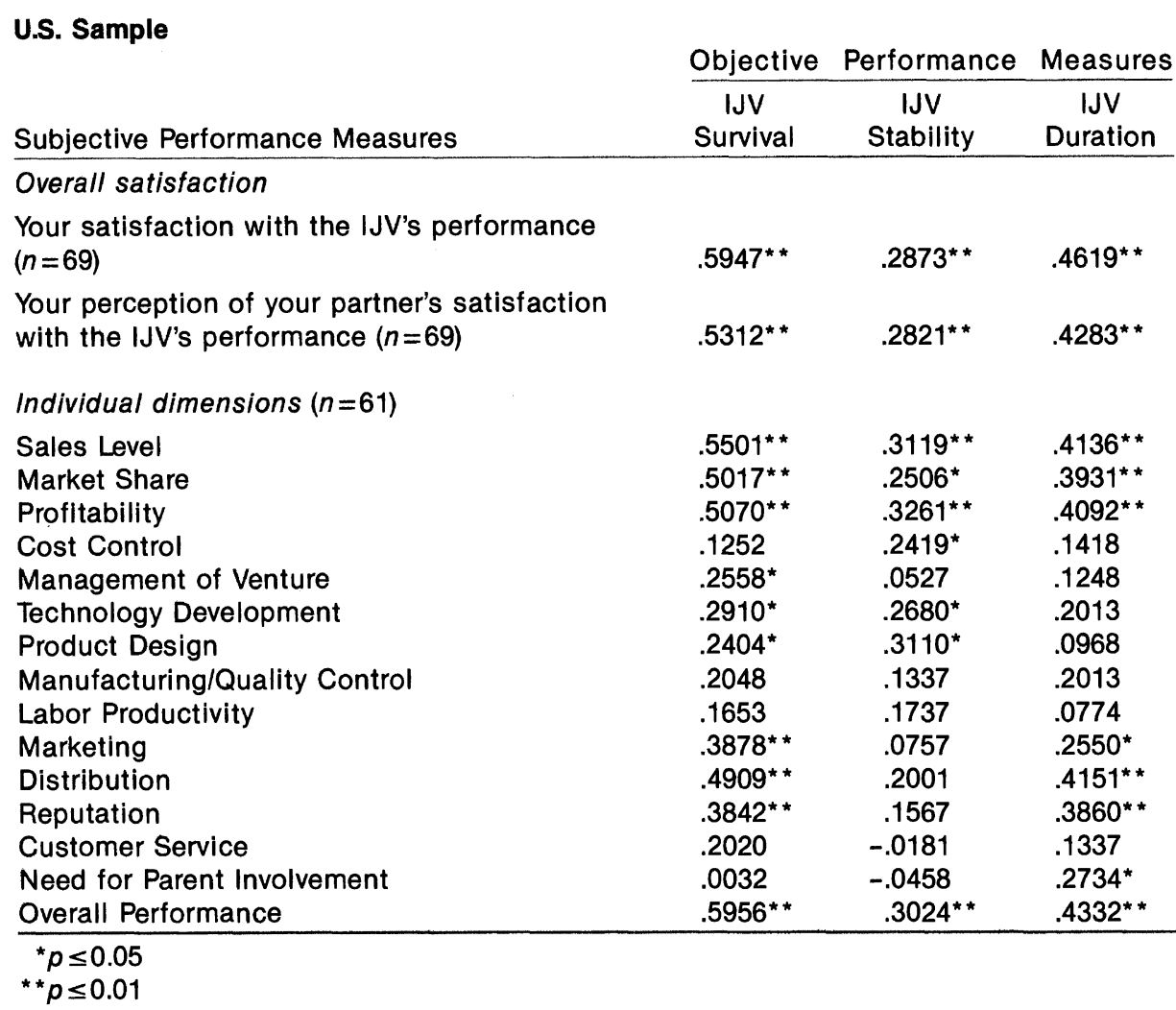

from similar national cultures (Table 2). In addition, the consistency between a parent's satisfaction and the partner's and IJVGM's perceptions of that parent's satisfaction was clearly more evident in IJVs involving parents located in North America and thus from similar national cultures. In all significant cases, correlations were stronger for this subset than for the overall sample (Table 4). The reciprocal argument also received support: when partners were not categorized as being from similar national cultures, or where one of the parents was from outside North America, there were significant yet smaller correlations between actual parent satisfaction and perceptions of that parent's satisfaction for all but one of the tested dimensions.

In conclusion, all five hypotheses received empirical support. Moreover, for both the substitutability of objective and subjective performance measures and the consistency among multiple respondents, correlations were generally greater than 0.50 . This was particularly noticeable in the case of the results for general dimensions of IJV performance. In this regard, the results surpass 0.40 , the average correlation coefficient found in 
TABLE 2

Spearman Rank Order Correlations Between Parent Firms' Assessments of Specific Aspects of IJV Performance

\begin{tabular}{lccc}
\hline Canadian Sample & $\begin{array}{c}\text { Total } \\
(n=16)\end{array}$ & $\begin{array}{c}\text { Similar National } \\
\text { Culture }(n=8)\end{array}$ & $\begin{array}{c}\text { Different National } \\
\text { Culture }(n=8)\end{array}$ \\
\hline Sales Level & $.720^{* *}$ & $.774^{* *}$ & $.550^{* *}$ \\
Market Share & $.627^{\star *}$ & $.814^{*}$ & .000 \\
Profitability & $.700^{* *}$ & $.913^{* *}$ & .538 \\
Cost Control & $.658^{* *}$ & $.719^{*}$ & .526 \\
Management of Venture & $.687^{\star *}$ & $.731^{*}$ & $.654^{*}$ \\
Technology Development & $.465^{*}$ & $.720^{*}$ & -.167 \\
Product Design & .077 & .278 & -.258 \\
Manufacturing/Quality Control & .373 & .045 & .668 \\
Labor Productivity & $.496^{*}$ & .500 & .455 \\
Marketing & .349 & $.819^{* *}$ & .063 \\
Distribution & -.113 & - & -.167 \\
Reputation & -.016 & -.093 & .081 \\
Customer Service & .262 & .354 & .145 \\
Need for Parent Involvement & $.709^{* *}$ & $.799^{* *}$ & .521 \\
Overall Performance & $.751^{* *}$ & $.876^{* *}$ & $.731^{*}$ \\
\hline
\end{tabular}

${ }^{*} p \leq 0.05$

$* * p \leq 0.01$

- Means correlation could not be calculated, since values were present only for a single row or column.

social sciences research [Nunnally 1978], as well as Cohen's [1977] criterion of 0.50 for qualifying as large correlations.

\section{DISCUSSION}

This study's objective was to examine the reliability of and correlation between various IJV performance measures, using data from two distinct but related samples of IJVs. The study's results have several important implications, particularly for selecting the appropriate research methodology to employ in studies examining the management of IJVs and other related cooperative ventures.

First, for the U.S. study, objective measures were found to be positively correlated, although not perfectly, with parent firms' reported satisfaction with IJV performance and with perceptions of the extent to which an IJV performed relative to its initial objectives. In the absence of other performance data, the use of objective measures as reliable performance surrogates may thus be justifiable. Such an argument seems particularly strong for a survival-based measure, which was the objective measure evidencing the strongest correlation with subjective IJV performance. This result suggests that IJVs perceived by their parents as performing more successfully were more likely to remain in operation than those IJVs that were evaluated as being less successful. Successful IJVs also tended to remain in operation for a longer period of time, a correlation which received support 
TABLE 3

Spearman Rank Order Correlations Between IJVGMs and Parents' Assessments of Specific Aspects of IJV Performance

\begin{tabular}{|c|c|c|}
\hline \multicolumn{3}{|l|}{ Canadian Sample } \\
\hline IJVGM & $\begin{array}{l}\text { Parent } 1 \\
(n=27)\end{array}$ & $\begin{array}{c}\text { Parent } 2 \\
(n=19)\end{array}$ \\
\hline Sales Level & $.8589 * *$ & $.9280^{* *}$ \\
\hline Market Share & $.8385^{\star *}$ & $.8232^{* *}$ \\
\hline Profitability & $.8901^{* \star}$ & $.8004^{* *}$ \\
\hline Cost Control & $.6781^{\star \star}$ & $.6311^{* *}$ \\
\hline Management of Venture & $.3725^{*}$ & $.6663^{* *}$ \\
\hline Technology Development & $.5077^{\star \star}$ & $.4714^{\star}$ \\
\hline Product Design & $.3913^{\star}$ & .2703 \\
\hline Manufacturing/Quality Control & $.4107^{\star}$ & $.5467^{\star *}$ \\
\hline Labor Productivity & $.5874^{\star \star}$ & $.6905^{\star *}$ \\
\hline Marketing & $.5492^{\star \star}$ & $.6751^{\star *}$ \\
\hline Distribution & .3257 & .3883 \\
\hline Reputation & $.5983^{\star \star}$ & .0000 \\
\hline Customer Service & .2993 & $.5111^{*}$ \\
\hline Need for Parent Involvement & $.5275^{\star *}$ & $.4192^{*}$ \\
\hline Overall Performance & $.7300^{* *}$ & $.8695^{* *}$ \\
\hline
\end{tabular}

${ }^{*} p \leq 0.05$

$* * p \leq 0.01$

from data on the IJV duration measure. However, the results for duration might be interpreted with some caution, since IJVs still in existence represented nearly half of the U.S. sample.

Of the three objective measures examined, the study's results suggest that the greatest level of caution may be warranted regarding use of the objective measure of IJV stability. Instability, or changes in IJV ownership structure, seemed to have a much less direct relationship with subjective measures of IJV performance than did either survival or duration-based measures. This result suggests that factors other than subjective performance could be correlated with IJV instability. For example, Blodgett [1987] argued that instability or changes in the IJV ownership structure could be interpreted as a function of the IJV partners' relative bargaining power and resource contributions to the venture, rather than IJV performance per se. Kogut's [1989] findings suggest it may also be a consequence of changes in the competitive rivalry between the partners. In sum, while instability may have some relationship with IJV performance, it appears desirable and indeed necessary for alternative explanations and variables to be taken into account as well.

Second, regarding data collection methodology, the appropriateness of using a single respondent for collecting performance data seemed to receive support from the Canadian study's results. For circumstances where pursuit of respondents from more than one of the entities in an IJV represents an impossible or extremely difficult proposition, use of a single respondent per IJV appears to allow researchers to obtain fairly reliable and efficient 


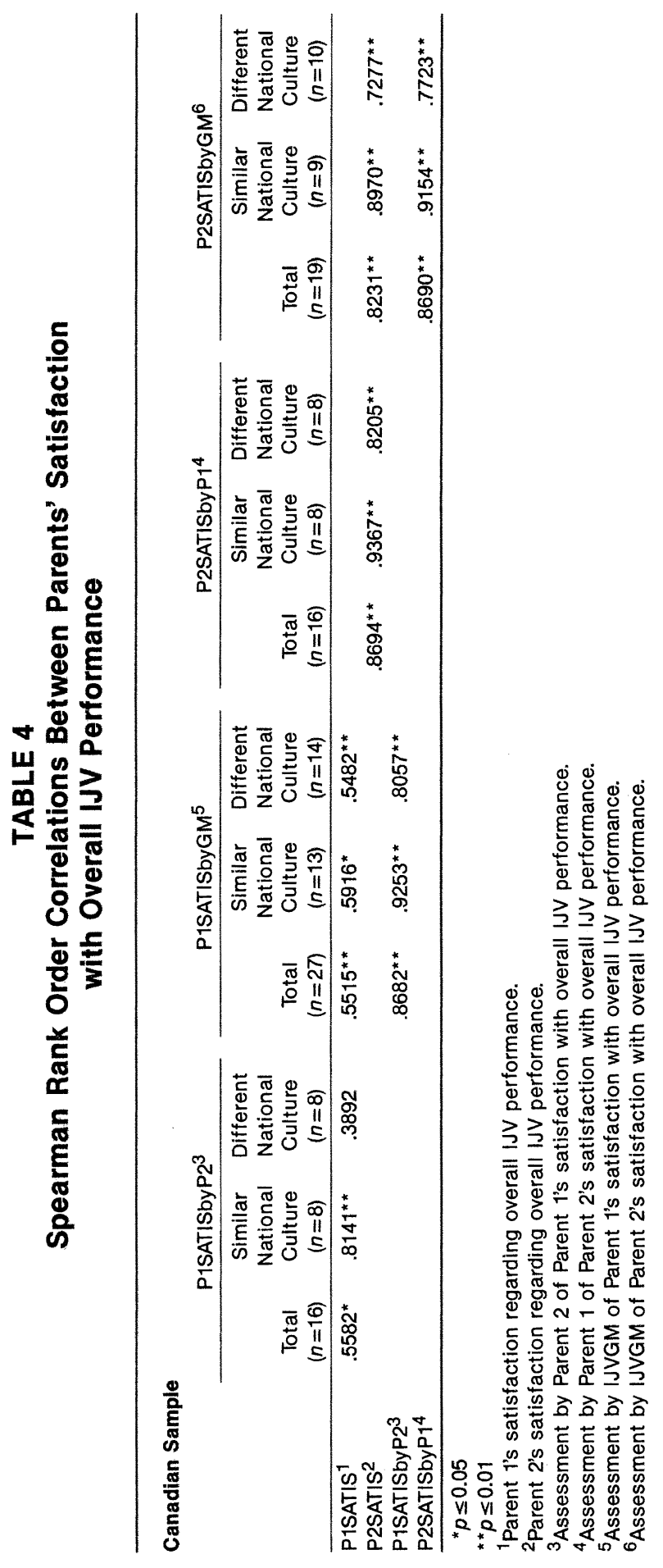


data for overall IJV performance. Reliance on a single parent company respondent as a data source appeared to be a justifiable option when the respondent represented one of the key stakeholders (i.e., the parent company executive with direct responsibility for the IJV). This also appeared to be the case when the parents were from the same or similar cultures or nations as the IJV, although the latter condition did not necessarily have to exist. However, differences in partners' evaluations were evident for more specific and detailed aspects of the IJVs. Consequently, parent firms appear to have both convergent and divergent interests in an IJV. While tending to agree on general aspects of an IJV's performance, partners also appear to evidence performance objectives and/or perceptions of their own that may not be identical, although not necessarily incompatible. These differences in partners' perceptions also suggest that examination of more specific aspects of an IJV and its performance might mandate the use of a multi-respondent approach in order to obtain reliable results.

Based on the Canadian study's results, utilization of the IJVGM for data collection may also constitute a reliable source of data. Indeed, there tended to be higher correlations between IJVGM and individual parent company evaluations than among evaluations of the respective parent companies themselves. Moreover, the IJVGM's and one partner's perceptions of the other partner's satisfaction were found to be quite similar. These correlations suggest that the IJVGM could provide fairly reliable data not only on each parent's satisfaction, but also on how each parent perceived its partner's satisfaction with IJV performance. Nevertheless, these findings might have been expected, since an IJVGM would typically require more extensive contact with the parent firms, as well as a more explicit and detailed understanding and appreciation of each parent's expectations and evaluations, than might be the case among executives of different parent companies.

However, this study was limited to data on IJVs that involved developed country parents. It also focused on recently formed IJVs that were still in existence or had been terminated only recently. The results may thus evidence higher correlations among respondents than might be the case for IJVs where at least one of the parent firms was from a less developed country. Similarly, correlations may be higher than they would otherwise have been for studies involving IJVs which were only hypothetical or simulated (e.g., Renforth [1974]; Chowdhury [1989]), IJVs whose operations had been terminated for a significant amount of time, or respondents who may not have had continuous intimate contact with the IJV (e.g., Tomlinson, [1970]). Despite these potential limitations, it remains that this research has provided empirical evidence regarding the reliability of and correlation between alternative measures of IJV performance, as well as providing insights into the relative utility of different data collection approaches, results that have not previously been reported in the IJV literature. 


\section{REFERENCES}

Anderson, Erin. 1990. Two firms, one frontier: On assessing joint venture performance. Sloan Management Review, 31(2): 19-30.

\& Baron Weitz. 1989. Determinants of continuity in conventional industrial channel dyads. Marketing Science, 8(4): 310-23.

Artisien, Patrick F.R. \& Peter J. Buckley. 1985. Joint ventures in Yugoslavia: Opportunities and constraints. Journal of International Business Studies, 16(1): 111-35.

Beamish, Paul W. 1984. Joint venture performance in developing countries. Unpublished doctoral dissertation, University of Western Ontario.

1985. The characteristics of joint ventures in developed and developing countries. Columbia Journal of World Busines, 20(3): 13-9.

Blodgett, Linda L. 1987. A resource-based study of bargaining power in U.S.foreign equity joint ventures. Unpublished doctoral dissertation, University of Michigan.

Brown, Lee T., Alan M. Rugman \& Alain Verbeke. 1989. Japanese joint ventures with Western multinationals: Synthesizing the economic and cultural explanations of failure. Asia Pacific Journal of Management, 6(2): 225-42.

Chakravarthy, Balagi. 1986. Measuring strategic performance. Strategic Management Journal, 7(5): 43758.

Chowdhury, M.A. Jafor. 1989. International joint ventures: Some interfirm-organization specific determinants of successes and failures-A factor analytic exploration. Doctoral dissertation, Temple University.

Cohen, Jacob. 1977. Statistical power analysis for the behavioral sciences. New York: Academic Press.

Contractor, Farok \& Peter Lorange, editors. 1988. Cooperative strategies in international business. Lexington, Mass.: Lexington Books.

Coopers \& Lybrand/Yankelovich, Skelly \& White. 1986. Collaborative ventures: A pragmatic approach to business expansion in the eighties. New York: Coopers \& Lybrand.

Dang, Tran Thanh. 1977. Ownership, control and performance of the multinational corporation: A study of U.S. wholly-owned subsidiaries and joint ventures in the Philippines and Taiwan. Unpublished doctoral dissertation. University of California, Los Angeles.

Davidson, William H. 1982. Global strategic management. New York: Wiley.

Deal, Terrence E. \& Allan A. Kennedy. 1982. Corporate cultures: The rites and rituals of corporate life. Reading, Mass.: Addison-Wesley.

Deloitte, Haskins and Sells. 1989. Teaming up for the nineties: Can you survive without a partner? New York: Deloitte, Haskins and Sells.

Dess, Gregory G. \& Richard B. Robinson, Jr. 1984. Measuring organizational performance in the absence of objective measures: The case of the privately-held firm and conglomerate business unit. Strategic Management Journal, 5(3): 265-73.

England, George W. 1975. The manager and his values: An international perspective from the United States, Japan, Korea, India and Australia. Cambridge, Mass.: Ballinger.

Franko, Lawrence G. 1971. Joint venture survival in multinational corporations. New York: Praeger.

Geringer, J. Michael. 1988. Joint venture partner selection: Strategies for developed countries. Westport, Conn.: Quorum Books.

. 1990. Trends and traits of Canadian joint ventures. Ottawa: Investment Canada.

\& Louis Hebert. 1989. Control and performance of international joint ventures. Journal of International Business Studies, 20(2): 235-54.

Geringer, J. Michael \& C. Patrick Woodcock. 1989. Ownership and control of Canadian joint ventures. Business Quarterly, 54(1): 97-101.

Gomes-Casseres, Benjamin. 1987. Joint venture instability: Is it a problem? Columbia Journal of World Business, 22(2): 97-107.

Good, Loretta. 1972. United States joint ventures and manufacturing firms in Monterrey, Mexico: Comparative styles of management. Unpublished doctoral dissertation, Cornell University. 
Harrigan, Kathryn R. 1986. Managing for joint venture success. Lexington, Mass: Lexington Books. 1987. Strategic alliances: Their new role in global competition. Columbia Journal of World Business. 22(2): 67-69.

1988. Joint ventures and competitive strategy. Strategic Management Journal, 9(2): 141-58.

Hergert, Michael \& Desmond Morris. 1988. Trends in international collaborative agreements. In Farok Contractor \& Peter Lorange, editors, Cooperative strategies in international business, 99-109. Lexington, Mass.: Lexington Books.

Hofstede, Geert H. 1980. Motivation, leadership and organization: Do American theories apply abroad? Organizational Dynamics, 9(1): 42-63.

Janger, Allen R. 1980. Organization of international joint ventures. New York: Conference Board.

Killing, J. Peter. 1983. Strategies for joint venture success. New York: Praeger.

Kogut, Bruce. 1986. Cooperative and competitive influences on joint venture stability under competing risks of acquisition and dissolution. Working paper, University of Pennsylvania, December.

1988. A study of the life cycle of joint ventures. In Farok Contractor \& Peter Lorange, editors, Cooperative strategies in international business, 169-85. Lexington, Mass: Lexington Books.

1989. The stability of joint ventures: Reciprocity and competitive rivalry. Journal of Industrial Economics, 38(2): 183-98.

Lecraw, Donald J. 1983. Performance of transnational corporations in less developed countries. Journal of International Business Studies, 14(1): 15-33.

Nunnally, Jum C. 1978. Psychometric theory (second edition). New York: McGraw-Hill.

Ouchi, William G. 1981. Theory z: How American business can meet the Japanese challenge. Reading, Mass.: Addison-Wesley.

Porter, Michael E. \& Michael B. Fuller. 1986. Coalitions and global strategy. In Michael E. Porter, editor, Competition in global industries, 315-44. Boston, Mass.: Harvard Business School Press.

Raveed, Sion. 1976. Joint ventures between U.S. multinational firms and host governments in selected developing countries: A case study of Costa Rica, Trinidad and Venezuela. Unpublished doctoral dissertation, Indiana University.

Renforth, William E. 1974. A comparative study of joint international business ventures with family firm or non-family firm partners: The Caribbean Community experience. Unpublished doctoral dissertation, Indiana University.

Reynolds, John I. 1979. Indian-American joint ventures: Business policy relationships. Washington, D.C.: University Press of America.

1984. The "pinched shoe" effect of international joint ventures. Columbia Journal of World Business, 19(2): 23-29.

Root, Franklin R. 1982. Foreign market entry strategies. New York: Amacon.

Schaan, Jean-Louis. 1983. Parent control and joint venture success: The case of Mexico. Doctoral dissertation, University of Western Ontario.

1987. International joint venture success measurement: Mexican evidence. Working Paper 8754. Ottawa, Canada: University of Ottawa.

Schein, Edgar H. 1985. Organizational culture and leadership. San Fransisco: Jossey-Bass.

Schneider, Susan C. 1988. National versus corporate culture: Implications for human resource management. Human Resource Management, 27(2): 231-46.

Stopford, John M. \& Louis T. Wells. 1972. Managing the multinational enterprise. New York: Basic Books.

Stuckey, John A. 1983. Vertical integration and joint ventures in the aluminum industry. Cambridge, Mass.: Harvard University Press.

Sullivan, Jeremiah J. \& Richard B. Peterson. 1982. Factors associated with trust in Japanese-American joint ventures. Management International Review, 22(2): 30-40.

Tomlinson, James W.C. 1970. The joint venture process in international business: India and Pakistan. Cambridge, Mass.: MIT Press. 